\title{
Corrosion issues in electronic equipments - an overview
}

\author{
R.J. Rathish, ${ }^{1}$ S.S. Prabha, ${ }^{1}$ R. Dorothy, ${ }^{2}$ S. Jancyrani, ${ }^{3 *}$ S. Rajendran, ${ }^{4 *}$ \\ G. Singh ${ }^{5}$ and S.S. Kumaran ${ }^{6}$ \\ ${ }^{1}$ PSNA College of Engineering and Technology, Dindigul, India \\ ${ }^{2}$ AMET University, Kanathur, East Coast Road, Chennai, India \\ ${ }^{3}$ PG Department of Chemistry, MV Muthia Government Arts College for Women, Dindigul, \\ India \\ ${ }^{4}$ Corrosion Research Centre, St. Antony's College of Arts and Sciences for Women, \\ Thamaraipadi, Dindigul, India \\ ${ }^{5}$ Vice Chancellor, Pondicherry University, Puduchcherru, India \\ ${ }^{6}$ School of Mechanical Engineering, VIT University, Vellore, India \\ *E-mail: jancyjayalakshmi@gmail.com, susairajendran@gmail.com
}

\section{Abstract}

Corrosion-induced failures are frequent in electronics products used in industrial environments. Now even in environments previously considered relatively benign with regard to electronics, serious corrosion problems are experienced as a direct result of RoHS (Restriction of the use of certain Hazardous Substances in electrical and electronic equipment) compliance. The very often used metals and alloys in electronic devices include aluminum, gold, copper, silver, tin, lead and their alloys. In electronic circuits the metals and alloys undergo various corrosion processes such as atmospheric corrosion, galvanic corrosion, electrolytic migration and fretting corrosion. Electronic products plays an un-replaceable role in recent society. But an increase in the number of people in the world having health problems caused by electromagnetic radiation pollution. Data obtained from sensors are useful in controlling corrosion of concrete. Climate changes which increase the levels of relative humidity and temperature, and thus causes corrosion in the industry and generates economic losses, which reduces competitiveness in the electronics industry in any region. Electroplated zinc finishes have been connected with the electronics industry for numerous years as a result of their outstanding corrosion resistance and moderately low cost. They are normally applied onto ferrous products to make available corrosion protection in a range of different environments. However, the formation of spontaneously grown whiskers on zinc-electroplated components, which are capable of resulting in electrical shorting or other destructive effects, can be highly challenging for the reliability of long life electrical and electronic equipment. The corrosion product creeps onto the solder mask surface and causes short circuits between the adjacent pads and traces. Creep corrosion of electronic assemblies is a growing problem. Commonly seen in harsh environments, the failures result from the formation of copper sulfide films on Printed Circuit Board assemblies in short period of time. Electronic control apparatus has been used for several decades to control processes and improve yields in the pulp and paper industry. Many electronic equipment manufacturers have changed from lead 
solder to other technologies which are more susceptible to gaseous corrosion. These types of connections can fail rapidly in mild and moderate environments, beforehand thought to cause troubles only after long periods of time.

Key words: electronic equipments, corrosion, galvanic corrosion, fretting corrosion, metals and alloys in electronic equipments.

Received: May 16, 2019. Published: October 8, 2019

doi: $\underline{10.17675 / 2305-6894-2019-8-4-2}$

\section{Introduction}

Numerous field failure returns of electronics are marked as "no failure found", yet many of these failures are likely due to corrosion, since corrosion related failures are not simply detected during subsequent failure analysis. In a number of cases failures are intermittent and take place because of service life conditions (humidity and contamination) where water film formation on the printed circuit board assembly (PCBA) leads to leakage currents ensuing in wrong output signal of the electronic device. If the leakage current itself will not result in malfunctioning of the electronics, the formed water film and potential bias of the PCBA will eventually lead to failure caused by more easy identifiable corrosion. Distinctive corrosion failure types seen in electronics are galvanic corrosion, electrochemical migration, and other types of bias induced corrosion.

The very often used metals and alloys in electronic devices include aluminum, gold, copper, silver, tin, lead and their alloys. Galvanic series performed in a flux solution is presented together with examples of galvanic corrosion causing failure of electronics. Failures that find root cause in the manufacturing process are many. For example flux activator related failures. Failures caused by service life conditions with high humidity and sulphur containing gaseous environments are also to be taken into account. The architecture of the PCBA (the placement of components) will affect its corrosion reliability. Infrared camera imaging is used to show the thermal distribution of the PCBA during power on periods and can reveal local cold spots on the PCBA being prone to condensation and corrosion.

The most common metals used in electronics are: plated tin (most susceptible), lead, copper (plated, cast, or wrought), nickel (plated), nickel-silver (18\% Ni), copper 110, copper-nickel 715, silver, gold and graphite (least susceptible).

Gold and silver are called noble metals because they are resistant to corrosion and acid. Copper and tin are considered base metals since they have a higher propensity to corrode. There are many types of corrosion; the following are typical in electronic packages using printed circuit boards or flexible circuits.

In electronic circuits the metals and alloys undergo the following types of corrosion. Atmospheric corrosion, galvanic corrosion, electrolytic migration and fretting corrosion. Several researches have been carried out in the field of corrosion in electronic instruments 
[1-32]. The recent developments in the field of corrosion issues in electronic industry are discussed.

\section{Corrosion issues in electronic equipments}

1. Data-driven machine learning approach for predicting volumetric moisture content of concrete using resistance sensor measurements

In sewerage industry, hydrogen sulfide induced corrosion of reinforced concretes is a global trouble. To achieve a complete knowledge of the spread of concrete corrosion, it is very important to monitor the grave factors such as damp. In this context, the authors have investigated the use of resistance measuring and processing for estimating the concrete moisture content. The behavior of concrete moisture with resistance and surface temperature are studied and the effects of $\mathrm{pH}$ concentration on concrete are analyzed. Gaussian Process deterioration modeling is carried out to predict volumetric moisture content of concrete, where the results from investigational data are used to train the prediction model [1].

\section{Use of a water-saving system to conserve ecosystems for water resources}

In the northwestern region of Mexico is border between Mexico and the United States (US), it is carried out an estimation of a possible problem of the small quantity of water that Mexico receives from our neighbor to the north, from the Rio Colorado (RC) from United States. Every so often USA sends unhygienic water to Mexico, by chemicals mainly because the hydric resource, comes from soil washing in the United States, from agricultural tricks. In addition, USA, projected a process to coat the All-American Canal (CTA), which has resulted in decreased of aquifers Mexicali Valley, generating worry in authorities and the population of Mexico. This has led to harm ecosystems and thus present climate changes that increase the levels of relative humidity $(\mathrm{RH})$ and temperature, and thus causes corrosion in the industry and generates economic losses, which reduces competitiveness in the electronics industry in this region [2].

\section{Zinc whisker growth from electroplated finishes}

Electroplated zinc finishes have been connected with the electronics industry for numerous years as a result of their outstanding corrosion resistance and moderately low cost. They are normally applied onto ferrous products to make available corrosion protection in a range of different environments. However, the formation of spontaneously grown whiskers on zinc-electroplated components, which are capable of resulting in electrical shorting or other destructive effects, can be highly challenging for the reliability of long life electrical and electronic equipment. The growth of zinc whiskers has been identified as the cause of some electrical and electronic failures in telecommunications and aerospace-based applications, with cost ranging from mild inconvenience to complete system failures. 
Investigators have been determined to address the problems induced by whisker growth since 1940s. Nevertheless, most research effort has been focused on tin whiskers, especially following European Union environmental legislation that restricted the use of lead $(\mathrm{Pb})$, which when alloyed with tin $(3-10 \%$ by weight $)$ provided effective tin whisker mitigation. Compared with tin whisker research, much less concentration has been paid to zinc whiskers. A number of mechanisms to explain zinc whisker growth have been proposed, but none of them are widely established and some are in disagreement with each other. The aim of this paper is to review the available literature in regard to zinc whiskers, to argue the reported growth mechanisms, to assess the effect of deposition parameters and to explore potential mitigation methods [3].

\section{Web-based national corrosion cost inventory system for Saudi Arabia}

The authors have developed a national web-based corrosion cost inventory system for the Kingdom of Saudi Arabia which can be used by any nation with little bit of customization. The research aims to converse these issues. The proposed system is designed to be divided into five major sectors namely, utilities, transportation, infrastructure, government, and production and manufacturing. Each of these major sectors is having further sub-sectors and then blown down to the industry and specific identity. The web-based application is developed using Dotnet on SQL server. The corrosion cost estimation procedures and corrosion rates in different sectors and sub-sectors have been made to order from the literature. The proposed urban system will enable end-users to provide corrosion and costrelated data through web-based online system. The input information from end-users will be authenticated by a corrosion auditor before finally entering into the database tables. The system is also capable of generating reports related to corrosion cost which the nation is paying with more details of corrosion costs borne by every sector and sub-sector. These reports will be helpful in creation decision to recognize the sector and sub-sectors which are more prone to corrosion and consuming more money to combat corrosion. Finally, the sectors and sub-sectors that are identified through the proposed organization could be put under thrust research areas to fight corrosion problem and hence reduce the corrosion cost burden in future [4].

\section{5. $20133 \mathrm{rd}$ International Conference on Machinery Electronics and Control Engineering, ICMECE 2013}

The extraordinary focus in this conference is on Machinery Electronics and Control Engineering. The topics contain: structural evolution of Fe-50Al/WC composite powder during mechanical alloyed process; EDM characteristics of inconel 718 and using manage chart for process stable; the wear mechanisms of diamond impregnated bit matrix; study of the interfacial reply between the Sn-3.5Ag solder and electroless Ni-P metallization; the influence of cutting parameters on pump thin-walled parts wounding force; the simulation experimental research on large diameter Fresnel lens mold machining; discussion on 
compensation factor for large-radius bending die; aluminum-clad invar super heat-resistant aluminium alloy stranded wire sag calculation; experiment on yield strength of PZT-4 piezoelectric generating column; the design of water dispenser remote wireless control system; flotation reagent progress and submission overview; select axial-symmetry cylinder-segments as basic scattering units in 2D photonic crystals; analysis for comparable in-plane elastic parameters of the honeycomb core; thermal analysis and failure behavior of 8YSZ thermal barrier coatings under thermal cycling tests; design of sound bird-scared piece of equipment based on MP3 [5].

\section{Substance flow analysis of cadmium in Korea}

Substance flow analysis (SFA) of cadmium in Korea was carried out to analyze and forecast cadmium flows, stocks, and future flows using both static and dynamic models. Cadmium is extensively used in industry due to its sturdy corrosion and chemical resistance at high temperature, excellent electrical conduction, and low melting-point. Cadmium is produced as a by-product from the production processes for zinc and lead ingots. It is used for Ni-Cd batteries, polyvinylchloride (PVC) stabilizers, alloy products, pigments, and others. This examines the current cadmium flows and stocks using static SFA, and aims in predicting the future cadmium flows and stocks in Korea using dynamic SFA. From the static model, 2820 tonnes of cadmium ingots were fashioned, 0.04 tonnes imported and 2740 tonnes exported in Korea in 2009. In addition, 81 tonnes of cadmium were used in the create of cadmium products: 80 tonnes for cadmium alloy products and 1 tonne for others. Finally, 175 tonnes of cadmium were imported into Korea for Ni-Cd batteries, 140 tonnes for PVC stabilizers, and 55 tonnes for pigments. Cadmium was used in a range of industries such as building (221 tonnes), electrics and electronics (130 tonnesincluding cadmium in imported products), transportation (30 tonnes) and others (30 tonnes). In 2009, 430 tonnes of industrial cadmium were discharged, with 10 tonnes being recycled and 420 tonnes discarded. From the dynamic model, cadmium stocks in Korea were expected to be about 5120 tonnes in 2009. The industrial consumption in 2030 will be reduced to only 110 tonnes, only $27 \%$ of the current consumption of 410 tonnes in 2009, due to DIRECTIVE 2002/95/EC of the European parliament of 27 January 2003 on the restriction of the use of certain dangerous substances in electrical and electronic equipment (RoHS). One possible solution to the Cd oversupply trouble is use in cadmium telluride photovoltaic (CdTe PV) systems which have low life cycle $\mathrm{Cd}$ emissions $(0.02 \mathrm{~g}$ $\mathrm{Cd} / \mathrm{GWh}$ ) and high end-of-life semiconductor recycling yields (95\%) [6].

\section{Investigation of factors that influence creep corrosion - INEMI project report}

Creep corrosion is a gathering transport process in which solid corrosion products (typically sulfide) migrate over a surface. The corrosion product creeps onto the solder mask surface and causes short circuits between the adjacent pads and traces. Creep corrosion of electronic assemblies is a growing problem. Commonly seen in harsh 
environments, the failures result from the formation of copper sulfide films on Printed Circuit Board (PCB) assemblies in short period of time. The iNEMI Creep Corrosion Group working on understanding this issue has recently communicated the possibility of simulating these corrosion signatures on electronic assemblies using a modified Mixed Flow Gas (MFG) test method. Since October 2009, iNEMI has organized phased projects to examine creep corrosion. Phase 1 consisted of a review to collect the data on creep corrosion failures and related factors in the electronics industry. The group also has communicating with ASHRAE, IPC 3-11g and Lawrence Berkley National Laboratory on associated issues. In Phase 2, the team analyzed the amount produced from Phase 1 and narrowed down the major factors that influenced creep corrosion. Phase 3 performs laboratory based experiments to further examine the sensitivities of the influencing factors identified in Phase 1 and 2, including surface finish, flux, solder mask geometry, solder paste exposure, reflow and wave soldering and MFG test conditions (corrosive gas concentration, humidity, temperature). Results from the electrical resistance measurements coupled with detailed fabric analysis of the corrosion products have been reported [7].

\section{Corrosion issues associated with RoHS can be fatal to electronic control equipment}

Electronic control apparatus has been used for several decades to control processes and improve yields in the pulp and paper industry. Control rooms lodging electronic equipment typically categorize the environment by the ISA-71.04-1985 standard for environments of electronic control equipment. This has served the industry well for a period of time. Nonetheless, the requirements of the European Union Restriction of Hazardous Substances Directive have caused many electronic equipment manufacturers to change from lead solder to other technologies which are more susceptible to gaseous corrosion. These types of connections can fail rapidly in Mild and Moderate environments, beforehand thought to cause troubles only after long periods of time [8].

\section{Packaging of high power semiconductor laser arrays using a novel macro-channel cooler}

High power semiconductor laser arrays have been extensively used in many fields, such as pumping solid state laser aerospace, industry, medicine and display. For many applications, high power semiconductor lasers operating quasi-continuous wave (QCW) mode are demanded. For QCW laser, the output peak power is higher and average power is low. Therefore, the transient thermal density is very high. The most general method of removing the large amounts of waste heat in a semiconductor laser package is by using commercially-available copper micro-channel coolers (MCC). However, due to the coefficient of thermal expansion (CTE) mismatching between copper and laser chip, hard solder cannot be directly used. On the other hand, indium solder has the difficulty of electro-thermal migration when the temperature grads were high in QCW mode. Furthermore, copper material is at risk to erosion and corrosion. To conquer these hurdles 
in many applications, a novel macro channel cooler (MaCC) was presented in this work. The thermal behavior of MaCC-packaged high power semiconductor laser arrays in QCW mode was studied using finite element analysis (FEA). A high power of $>250 \mathrm{~W}$ QCW semiconductor laser array/bar using hard solder was fabricated. The performances of laser arrays, as well as output power, slope efficiency, threshold, conversion efficiency, spectral width, near field, lifetime etc. were characterized. The precise results indicated that the output power of a MaCC- packaged high power semiconductor laser array was very close to that of copper micro-channel cooler. Based on MaCC-packaged single laser array/bar, multiple-bar stack and two dimension area array lasers with output powers of more than a few kilowatts and numerous tens of kilowatts were fabricated [9].

\section{Study on zero discharge technology of wastewater from power plant}

This electronic article is a "live" template. About 60 percent or 70 percent of the cities in China are short of water in different degree, thus the water resource is very shortage in China. The problem of water shortage has limited the industrial development. The matter is more than ever severe in North China and the area with water shortage areas. It is critical to increase the concentrated ratio of the circulating cooling water and decrease the wastewater liberation for the power plant, where the circulating cooling water system is used. According to the characteristic of the wastewater in the power plant at present, the problems of the optimization of the wastewater treatment are put forward in this paper. What's more, the technology of staged concentration of circulating water used for supplying water is designed, viz. the circulating cooling water is concentrated in stages and operation in series with the supplying water. The practical engineering experience in a certain power plant, indicates that it is profitable for the technology of the supplying water being series-wound concentrated stepwise. With the utilize of this technology, the number of the discharge of wastewater is reduced, all of which reveals the social, economical and environmental profit [10].

\section{What's creeping around in your data center?}

The European Union (EU) directive 2002/95/EC "on the Restriction of the use of certain Hazardous Substances in electrical and electronic equipment" or RoHS was implemented in July 2006. Nonetheless, this was only the first of many RoHS(-like) regulations that have been passed or are being considered in numerous countries. The aim being shared by approximately all RoHS legislation is the elimination of lead in electronic products. These policies are now generally referred to as the RoHS Directive and are often referred to as "Lead-Free" legislation. A printed circuit board, or PCB, is used to mechanically support and electrically fix electronic components using conductive pathways laminated onto a non-conductive substrate. PCBs have conducting layers on their surface typically made of thin copper foil which if left insecure, will oxidize and deteriorate. Research has shown that printed circuit boards made using lead-free materials can be more susceptible to 
corrosion than their tin/lead counterparts and it was soon discovered that lead-free products with immersion silver (ImmAg) surface finish will creep corrode in high sulfur environments. The greater part of creep corrosion failures occurred on hard disk drives (HDD), graphic cards, and motherboards in desktop or workstation systems (only those with ImmAg PCB finish were affected). Corrosion-induced failures are frequent in electronics products used in industrial environments. Now even in environments previously considered relatively benign with regards to electronics corrosion are experiencing serious problems as a direct result of RoHS compliance. Data centers in several urban locations have reported failures of servers and hard disk drives due to sulfur corrosion. Gaseous contamination can result in intermittent equipment glitches, unplanned shutdowns, or failure of critical systems that often result in significant business and monetary loss. Desktop and laptop computers, servers, data communications (datacom) equipment and other information technology (IT) equipment are now at risk due to RoHS. There are indications that this may even trickle down into personal computers and electronic devices. Manufacturers have to comply with RoHS if they want to persist in to do business in the EU, China, etc., and many have taken the ImmAg route as their path to compliance. This has taken care of one matter but has presented new challenges with regards to equipment reliability [11].

\section{Study on pollution control measures of electromagnetic radiation based on ideas of energy-saving}

Electronic products plays an un-replaceable role in recent society. But an increase in the number of people in the world having health problems caused by electromagnetic radiation pollution. Based on test reports and large numbers of literature and data about electromagnetic waves, the types and characteristics of electromagnetic radiation pollution had been analyzed. And the body jeopardize of electromagnetic radiation pollution were studied systematically. On this basis, the pollution control measures of electromagnetic radiation were finished an in-depth dissertation to guard the physical condition of people [12].

\section{How the changing regulatory landscape is affecting equipment reliability}

The European Union directive 2002/95/EC "On the Restriction of the use of certain Hazardous Substances in electrical and electronic equipment" (RoHS) was implemented in July 2006. This was the first of numerous regulations with the shared aim of the removal of lead in electronic products. However, ongoing research has shown that printed circuit boards made using lead-free materials can be more susceptible to corrosion and that leadfree products with immersion silver ( $\mathrm{ImmAg}$ ) surface finish are particularly susceptible to corrosion in towering sulfur environments - the same environments found in pulp and paper manufacturing. The authors have discussed RoHS fulfillment issues and the resulting potential for corrosion-related problems. Data will be presented that illustrates corrosive 
environments survive in locations that would otherwise be considered benign if not for the changes in electronic equipment mandated by RoHS legislation. However, these problems can be addressed by continuous monitoring of the environment and the control of corrosive contaminants where indicated. Ultimately, the successful implementation of an electronic equipment reliability program requires; (1) knowledge and understanding that corrosion of electronic equipment is a grave problem, (2) commitment to a monitoring program to portray the potential for electronic equipment failure, (3) commitment to an integrated contamination control system, and (4) commitment to take corrective action whenever required [13].

\section{Corrosion of electronic control systems in gas treating environments}

The use of microelectronic computer control systems in field locations has developed swiftly over the last 15 years. These distributed control systems (DCS) are far more prone to corrosion harm than earlier control systems. Of particular apprehension are locations where sulfur species may be present such as hydrogen sulfide, sulfur dioxide, or elemental sulfur. Failures of critical components may happen in as little as three months in locations where humidity, temperature, and corrosive gases are not adequately controlled. Temporary relief may be obtained by the use of vapor phase corrosion inhibitor (VCI) powders and sprays. A more permanent solution is the installation and preservation of an adequate air handling system that removes pollutants and controls humidity and temperature. The authors have reported a number of different failures that occurred in one plant including general corrosion of circuit boards and a history module and corrosion fatigue of copper conductor wires on an electronics circuit board. Field data on unusual solutions to the difficulty are presented [14].

\section{Sn-Zn low temperature solder}

Low temperature soldering is one of the key technologies before the accomplishment of total lead-free change in electronics industries. While $\mathrm{Sn}-\mathrm{Zn}$ eutectic alloy has exceptional properties as low temperature solder, it has some drawbacks. Damage by heat exposure and corrosion in humidity are two of the main concerns. $\mathrm{Zn}$ has an imperative role in chemical properties. The material physical properties, wetting, chemical stabilities and various reliabilities have been well understood on this alloy system through the numerous past works. The understanding of both materials and processing aspects enables one to manufacture sound electronic products without any grave problems. The basic properties and the recent understandings on the boundary of the application of this solder have been reported [15]. 
16. Practical approaches to measuring $p H$ of condensate and feed water in the power industry

$\mathrm{pH}$ is broadly used to monitor and control the stability of corrosion control chemicals in the pure water systems found in electric power production plants. This paper will converse the problems associated with this measurement and focus on practical solutions. A brief discussion of $\mathrm{pH}$ technology and the difficulties encountered with high purity, low conductivity water will be presented. The value of good $\mathrm{pH}$ measurement and control will be discussed in stipulations of plant chemistry, scaling and corrosion control, protecting equipment and preventing spontaneous outages. Emphasis will be placed on practical, cost effective approaches to the selection, installation, and continuation of $\mathrm{pH}$ measuring equipment [16].

\section{TFT technology for large area electronics}

Microelectronics and, predominantly, silicon integrated circuit microelectronics, has produced remarkable capabilities over the last 40 years. There are numerous indicators of this, but best summarized as "Moore's Law". While more transistors $/ \mathrm{cm}^{2}$ is the driving force, the microelectronics-based display industry has, for over a decade also explored alternate directions - larger and larger "chips" and/or another substrates. Major R\&D investment has been made in migrating from a glass substrate "chip" to a plastic one in order to achieve increased functionality (again without increasing the transistors $/ \mathrm{cm}^{2}$ ). The relatively low cost manufacturing process used for displays has fashioned significant interest in applying this form of microelectronics to other classes of problems. An illustration is an image array. Here the amorphous TFT can also be used as a light sensor. This leads to digital x-rays with many advantages over the conventional film based methods. The sensor function might also cover other parts of the EM spectrum to provide a large area IR imager or RF antenna array (communications and radar) [17].

\section{Inkjet printing of well-adapted PEDOT-PSS dispersions}

Poly(3,4-ethylenedioxythiophene)polystyrene sulfonic acid (PEDOT-PSS) is a well-liked conductive polymer that finds widespread use in the fields of polymeric electronics and exhibit applications. Its major recompense lie in the suitability for flexible electrical devices and the relatively simple deposition process capabilities with techniques such as inkjet printing. However, the deposition of PEDOT-PSS dispersions with inkjet printheads can cause a number of problems due to possible interaction of the fluids with the printhead, and due to poor inkjet functionality and layer formation on the substrate. In the present work we have modified PEDOT-PSS dispersions for improved performance in a Xaar-type piezoelectric inkjet printhead, in particular for high quality drop formation and for reduced corrosion of the inkjet printhead. At the same time the best PEDOT-PSS inks regarding layer formation and conductivity were identified. As an application illustration, a passive 
LCD device incorporating an inkjet printed PEDOT-PSS electrode pattern that was produced with an adapted PEDOT-PSS ink is accessible [18].

19. Effect of sacrificial anodic fillers on contact resistance stability of electrically conductive adhesives onto lead-free alloy surfaces

Electrically conductive adhesive (ECA) is a hopeful substitute for the toxic lead-based soldering materials for electronics interconnects. However, its unstable electrical conductivity has long been a haunting problem. The galvanic corrosion has been recognized as the major mechanism answerable for this conductivity decay at the ECA/pad interface. Applying a more active metal or alloy on a dissimilar metal couple in electrically contact can guard the comparably active metal from galvanic corrosion. Using sacrificial metals in ECA has been freshly studied and demonstrated to be an efficient method to protect the metal surfaces from corrosion. In this study, powders of aluminum, magnesium, zinc and two alloys were used in ECA as the sacrificial metals and applied on five typical and lead-free pad/lead surface finishes (tin/lead, copper, nickel/gold, tin/silver, and tin/silver/copper). The electrode potential measurement of these metals, alloys, and ECAs were conducted, and reliabilities of mass resistivity and contact resistance of ECA/metal surface pairs with respect to $85^{\circ} \mathrm{C} / 85 \% \mathrm{RH}$ aging were studied. After 500 hours of aging, the two alloys added significantly covered up the increase of the contact resistance on all tested metal surfaces with the Alloy 1 being the better one. The $\mathrm{Al}$ and Mg, added ECA and $\mathrm{Zn}$ and $\mathrm{Al}$ added ECA also showed obvious positive effects on slowing down the contact resistance increase. The order of reliability of contact resistance was found in chance with the arrange of electrode potential data of all metal, alloys and ECAs [19].

20. Flux-free process for placement and attach of solder balls to wafers, flip chips and all $B G A$ packages

The recent method used by industry for solder ball placement and accessory on wafers and BGA packages produces unacceptable production yields, as the existing process requires the use of flux. When flux liquefies during reflow soldering, the bonds between the flux, balls and pads are shattered and the balls are free to move. Defects such as vacancies, adjacent ball bridging, loss of positional accuracy and voids are created. Also, flux residues are not always completely removed during post-solder cleaning processes due to these voids, and high resistance shorts and/or corrosion may result. Demand for flip chip technology and BGA devices has gradually increased and more proficient high volume manufacturing assembly methods must be urbanized to keep pace. Ball attachment production yields also must be improved so that manufacturing costs can be reduced. In response, SST has developed a new and more cost-effective method of solder ball placement and attachment to wafers and to plastic and ceramic packages for BGA applications. The new method virtually eliminates the problems associated with the current methods. The SST process uses specially designed tooling for loading and precise holding 
of solder balls in the required position during dispensation. The soldering operation is performed without flux in a controlled atmosphere. As a result, pre-solder paste screening and post-solder cleaning operations are not required. The SST ball attachment process for wafers is performed at the wafer level preceding to singulation, thereby maximizing production capability. The ball attachment process for BGA packages is also incredibly efficient [20].

\section{EMC systems engineering}

An impression of the EMC problem, new United States governmental requirements, and systems design, are provided. The systems plan presentation covers PCB design considerations, differential and common mode outline and cable EMC hardening, and protecting for RF emission and susceptibility control. The shielding discussion covers aperture controls as well as mechanical and corrosion design. Shielding design is emphasized in the presentation because it can be applied to existing systems lacking impacting circuit procedure [21].

\section{Corrosion properties of new magnesium alloys}

Magnesium alloys are being used in a broad multiplicity of structural applications in the automotive, aerospace, electronics, and consumer products industries. While the enlargement of these applications has been driven primarily by weight savings, other advantages of magnesium alloys have played an important role. A major advantage is their unique appropriateness to the die casting process, allowing high rate production of near-net shape parts. Along with greater die life, this yields production cost savings that can more than offset the raw material charge benefit of competitive die cast aluminum alloys. Excellent machinability and superior damping properties are other important properties of these alloys. An outstanding feature of the new generation of magnesium alloys is their better resistance to salt water corrosion. Initially developed in AZ91D, this property has been extended to alloys of lower aluminum content which offer specific advantages such as greater ductility and impact strength, higher damping, or improved creep strength. The corrosion behavior of these alloys is reviewed. The exacting problem of galvanic compatibility of magnesium, especially with ferrous metal fasteners, is discussed and approaches to the solution are evaluated [22].

\section{New method of water cleaning for circuit substrate}

Soldering technology using rosin flux has been developed in the electronics industry due to the advantageous individuality that it does not cause corrosion of conductors and that the stability of the flux is high. Recently, however, the solvent which is commonly used for post-cleaning of rosin flux residue (CFC-113) has been linked to environmental pollution, especially ozone depletion. Many engineers are now wrestling with the tricky problem of rising an another cleaning method. Until now various kinds of water soluble flux have been 
practically used only for the wave soldering process. Utiliation of the same type of flux in solder paste for the reflow soldering process has not been successful. This is because the solder particle and the flux of solder paste are required to get in touch with each other under chemically stable conditions for extended periods, and this technical barrier made it fairly difficult to make practical use of solder pastes containing water soluble flux. We have developed a water soluble flux stick that has excellent characteristics equivalent to those of rosin flux by improving the activator and rheological modifier. Also, we have simultaneously developed original and novel cleaning equipment. The new solder paste and cleaning method was applied to on board power supply (OBP) products, and these products passed $1500 \mathrm{~h}$ of temperature, humidity, bias (THB) testing. This ensures that the new method, combining the newly developed water soluble paste and the cleaning equipment, can make available the same reliability of reflow soldered product as that of the product processed by the conventional cleaning method using rosin flux and solvent [23].

\section{Assessing the coating condition of buried pipelines}

Assessing the coating condition and possible corrosion risk of buried pipework is a familiar problem within the petrochemical industry. A survey technique originally developed to monitor coating conditions and situate defects on cross-country pipelines has lately been tailored to suit plant situations. The procedure employs C-SCAN, a computerized system manufactured by Dynalog Electronics of Bristol, to monitor the variations in magnetic flux produced by changes in coating condition. The technique has proved triumphant in detecting cracking due to aging of coating materials, tears due to appliance damage during pipe laying, indentations due to settlement of pipeline or use of unsuitable backfill materials, and coating disbondment due to poor surface preparation or reduced control of applied cathodic defense [24].

\section{Understanding vapour phase reflow soldering}

The authors have focused on topics that will aid in ensuring optimization of the reflow process. The problems, their causes and solutions, will be discussed in their context, that is, those problems which can be prevented during devise and assembly steps and those encountered during the reflow progression regardless of the heating method chosen. Some of the topics to be discussed will include tombstoning and component movement, solder joint honesty (appearance of intermetallics voids), solder wicking, thermal shock, safety, corrosion and operating cost. In addressing these topics this work will consolidate experimental results and production experience of a number of most important users and vendors contained by the electronics industry [25].

\section{Research to develop guidelines for cathodic protection of concentric neutral cables}

The augmented incidence of concentric impartial wire corrosion and the problems connected with severed wires led the Electric Power Research Institute to begin Research 
Project RP1049-1 (Development of Guidelines for Cathodic Protection of Concentric Neutral Cables). The aims of this project are to (1) determine and statistically analyze data associated with corrosion of the concentric neutral $(\mathrm{CN})$ wires of direct covered primary cables, and (2) develop guidelines for cathodic protection of $\mathrm{CN}$ cables for the electric utility industry. The authors have explained preliminary field testing conducted at 36 test excavations in California, Oklahoma, and North Carolina by the Pacific Gas and Electric Company (PGandE). It also includes information of the electrochemical, chemical, bacteriological, and sieve analyses of native soils and imported backfill samples. Up to 129 values were determined for each test excavation and stored as a data bank. The analysis of data gathered, cathodic safety design criteria, and beginning cathodic protection fitting results are explained [26].

\section{Greater environmental protection for electrical equipment through new technology}

Corrosive environments have extended accessible problems in application, installation, and maintenance of electrical equipment. The causes of corrosion and the means taken to date to contest corrosive environments are briefly reviewed. The application of new technology in the glass-reinforced polyester plastics field is described as a solution to the difficulty of long-term protection of electrical equipment installed in aggressive environments. This new technology involves the use of chemical thickening of special polyester resins suitably formulated to provide high levels of structural strength and corrosion resistance both indoors and outdoors. Data are presented on the environmental confrontation of the chemically thickened glass-reinforced polyester systems, and these are interpreted in terms of the diffusion of the environment into and out of the plastic. Examples are given of the application of chemically thickened glass-reinforced plastics in grave duty industrial plugs and receptacles, industrial category light reflectors, and enclosures for electrical equipment. The degree of guard afforded by the chemically thickened glass-reinforced plastic is significant in electrical installations in the petroleum, petrochemical, food, drug, fertilizer, and other progression industries [27].

28. Corrosion case histories: The cure of corrosion in mercury diffusion pumps used for valve manufacture

The central research laboratory of Philips Electrical Industries Pty. Ltd., a large Australian manufacturing organisation, is often required to act in a consultative aptitude to solve problems directly linked to production. In this case history, corrosion inside the waterjacketing of water-cooled mercury dispersion pumps used in the final stages of valve creation by an electronics concern was arrested after a systematic examination of the contributory reactions [28].

\section{Acknowledgement}

The authors are thankful to their respective managements for their help and support. 


\section{Reference}

1. K. Thiyagarajan, S. Kodagoda and N. Ulapane, Data-driven machine learning approach for predicting volumetric moisture content of concrete using resistance sensor measurements, Proceedings of the 2016 IEEE 11th Conference on Industrial Electronics and Applications, ICIEA 20167603783, 2016, 1288-1293. doi: 10.1109/ICIEA.2016.7603783

2. G. López, M.M. García, L.A. Gameros and A.P. De La Rocha, Use of a water-saving system to conserve ecosystems for water resources, Tecnologiay Ciencias del Agua, $2015,6,125-135$.

3. L. Wu, M.A. Ashworth, and G.D. Wilcox, Zinc whisker growth from electroplated finishes, Trans. Inst. Met. Finish., 2015, 93, 1-8. doi: $\underline{10.1179 / 0020296715 Z .000000000227}$

4. S. Rehman and L.M. Al-Hadhrami, Web-based national corrosion cost inventory system for Saudi Arabia, Anti-Corros. Methods Mater., 2014, 61, 72-92. doi: 10.1108/ACMM-04-2013-1254

5. W. Wang, H. Zhang and Z. Wang, Progress in magnesium alloys reinforced by long period stacking ordered structure, Xiyou Jinshu/Chinese Journal of Rare Metals, 2014, 38, no. 1, 138-145.

6. K. Cha, M. Son, Y. Matsuno, V. Fthenakis and T. Hur, Substance flow analysis of cadmium in Korea, Resour., Conserv. Recycl., 2013, 71, 31-39. doi: 10.1016/j.resconrec.2012.11.005

7. G. O'Malley and $\mathrm{H}$. Fu, Investigation of factors that influence creep corrosion INEMI project, Proceedings of the IEEE/CPMT International Electronics Manufacturing Technology (IEMT) Symposium, 6521824, 2012. doi: 10.1109/ESTC.2012.6542088

8. W. Brad and W.B.M. Stanley, Corrosion issues associated with RoHS can be fatal to electronic control equipment, NACE - Int. Corros. Conf. Ser., 2010.

9. J. Wang, Z. Yuan, L. Guo, X. Li, L. Xiong, Y. Zhang, C. Peng and X. Liu, Packaging of high power semiconductor laser arrays using a novel macro-channel cooler, Proceedings - 2010 11th International Conference on Electronic Packaging Technology and High Density Packaging, ICEPT-HDP 20105582358, 2010, 92-97. doi: 10.1109/ICEPT.2010.5582358

10. X. Zhang, G. Shi and S. Liu, Study on zero discharge technology of wastewater from power plant, Proceedings of the 2010 5th IEEE Conference on Industrial Electronics and Applications, ICIEA 2010, 5515662, 2010, 911-914. doi: 10.1109/ICIEA.2010.5515662

11. C. Muller, What's creeping around in your data center?, ASHRAE Trans., 2010, 116, PART 1, 207-222. 
12. Z.-F. Zhang, J.-J. Zhang and Q.-Z. Ma, Study on pollution control measures of electromagnetic radiation based on ideas of energy saving, Asia-Pacific Power and Energy Engineering Conference, APPEEC 5448413, 2010. doi: 10.1109/APPEEC.2010.5448413

13. G. Crosley and C. Muller, How the changing regulatory landscape is affecting equipment reliability, TAPPI Press - TAPPI Engineering, Pulping and Environmental Conference 2009 - Innovations in Energy, Fiber and Compliance, 2009, 2, 775-823.

14. R.D. Tems, G.R. Lobley and S. Mehta, Corrosion of electronic control systems in gas treating environments, NACE - Int. Corros. Conf. Ser., 2007, 074001-0740015.

15. K. Suganuma and K.-S. Kim, Sn-Zn low temperature solder, J. Mater. Sci.: Mater. Electron., 2007, 18, 121-127. doi: 10.1007/s10854-006-9018-2

16. J.H. Yarbrough and J.P. Connelly, Practical approaches to measuring $\mathrm{pH}$ of condensate and feed water in the power industry, 16th Annual Joint ISA POWID/EPRI Controls and Instrumentation Conference and 49th Annual ISA Power Industry Division, POWID Symposium 2006, 2006, 2, 778-788.

17. R. Reuss, TFT technology for large area electronics, Int. Semicond. Device Res. Symp. 2005, 2005, 1596011, 126.

18. W. Voit, H. Sjöblom, L. Wang, A. Fogden, and W. Zapka, Inkjet printing of welladapted PEDOT-PSS dispersions, Int. Conf. Digital Print. Technol., 2004, 226-231.

19. H. Li, K.-S. Moon and C.P. Wong, Effect of sacrificial anodic fillers on contact resistance stability of electrically conductive adhesives onto lead-free alloy surfaces, Proc. - Electron. Compon. Technol. Conf., 2003, 1373-1377. doi: 10.1109/ECTC.2003.1216473

20. R. Ramos, Flux-free process for placement and attach of solder balls to wafers, flip chips and all BGA packages, Proceedings of the IEEE/CPMT International Electronics Manufacturing Technology (IEMT) Symposium, 1998, 24-33. doi: 10.1109/IEMT.1998.731008

21. R.W. Brewer, EMC systems engineering, Conference Proceedings - IEEE SOUTHEASTCON, 1997, 341. doi: 10.1109/SECON.1997.598708

22. D. Hawke and A. Olsen, Corrosion properties of new magnesium alloys, SAE [Tech. Pap.], 1993.

23. N. Takayama, T. Sugiyama, K. Takahashi, New Method of Water Cleaning for Circuit Substrate, IEEE Transactions on Components, Hybrids, and Manufacturing Technology, 1990, 13, 685-692. doi: $10.1109 / 33.62580$

24. Anon, Assessing the coating condition of buried pipeline, Process Eng. (London), 1988, 69, 47.

25. C. de Winter and K.R. Seidinger, Understanding vapour phase reflow soldering, Brazing Soldering, 1987, pp. 4-5, 9. 
26. J.A. Hanck, G. Nekoksa, Research to develop guidelines for cathodic protection of concentric neutral cables, IEEE Transactions on Power Apparatus and Systems PAS, 1982, 101, 1878-1887. doi: 10.1109/TPAS.1982.317459

27. G.J. Goepfert and D.J. Smith, Greater Environmental Protection for Electrical Equipment Through New Technology, IEEE Transactions on Industry Applications IA, 1976, 12, 28-35. doi: 10.1109/TIA.1976.349382

28. B.W. Gooden, Corrosion case histories: The cure of corrosion in mercury diffusion pumps used for valve manufacture, Anti-Corros. Methods Mater., 1965, 12, 16-18.

29. https://www.allflexinc.com/blog/corrosion-considerations-for-electronic-packages/

30. http://orbit.dtu.dk/files/100370544/Corrosion_in_electronics.pdf

31. http://www.celcorr.com/paper-DMS.pdf

32. http://corrosion-doctors.org/Forms-galvanic/galvanic-corrosion.htm 